\title{
LA PIEDRA COMO SÍMBOLO DE IDENTIDAD, FORTALEZA Y TRADICIÓN EN LA CULTURA MAYA QUICHÉ
}

Mayela Vallejos Ramírez

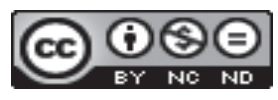

Esta obra está bajo una licencia Creative Commons

Reconocimiento-No Comercial-Sin Obra Derivada 



\title{
LA PIEDRA COMO SÍMBOLO DE IDENTIDAD, FORTALEZA Y TRADICIÓN EN LA CULTURA MAYA QUICHÉ
}

\author{
THE STONE AS A SYMBOL OF IDENTITY, STRENGTH AND \\ TRADITION IN MAYAN QUICHE CULTURE
}

\author{
Mayela Vallejos Ramírez
}

\begin{abstract}
RESUMEN
En este artículo se analiza el simbolismo que ejerce la piedra en algunas culturas antiguas (ancestrales americanas), específicamente dentro de la cultura maya, a través de los poemas Piedra $A B^{\prime} A J$. de la poeta maya quiché, Rosa Chávez. En esta colección, nos encontramos con una fuerte voz poética que hace un llamado a su pueblo para mantener viva la memoria de sus ancestros y recuperar la identidad perdida. El poemario también incursiona en una serie de ritos que nos plasma la esencia de su cultura y la relación que mantienen los miembros de estas sociedades con la naturaleza misma.

Palabras clave: piedra, maya quiché, identidad, conciencia, ancestro.
\end{abstract}

\begin{abstract}
This article analyzes the symbolic role played by rocks in several ancient cultures, specifically in the Mayan culture through the poems of Piedra $A B^{\prime} A J$ of the Mayan quiche poet, Rosa Chavez. In this collection, we find a strong poetic voice in which Chávez pleads to sustain the memory of her ancestors and to recuperate their history. The collection also allows us to familiarize ourselves with a series of Mayan rituals that portray the essence of that culture and the relation its inhabitants had with nature itself.

Key words: stone, maya quiche, identity, consciences, ancestor.
\end{abstract}

La piedra es un símbolo universal que se ha usado a través de la historia de la humanidad como signo de lo eterno. Desde el principio de los tiempos, los seres humanos se han visto atraídos por este elemento, quizás por su capacidad para mantenerse intacta ante los embates de la vida y por su gran resistencia. En algunas culturas como la celta, la piedra ha tenido un significado de lo eterno y normalmente la usaban para marcar un lugar especial

Dra. Mayela Vallejos Ramírez. Colorado Mesa University. Profesora catedrática. Department of Languages, Literature, and Mass Communications. Estados Unidos.

Correo electrónico: mvallejo@coloradomesa.edu

Recepción: 13- 12- 2014

Aceptación: 30- 01- 2015 
para que los espíritus vinieran a convivir con ellos, como es el caso de "Stonehenge" que se cree que fue un templo ceremonial y astronómico. La cultura irlandesa, escocesa e inglesa se ha visto fuertemente marcada por este elemento y lo ha conservado en muchos de sus rituales hasta el presente. La piedra de Scone, por ejemplo, ha jugado un papel muy importante para la realeza escocesa e inglesa como símbolo de poder y sabiduría. Se dice que "el mismo San Patricio, patrono evangelizador de Irlanda y los celtas hacia el año 400, la bendijo para su uso en las coronaciones. Los monarcas debían sentarse sobre la piedra para ser coronados y según la tradición, cuando el rey elegido era el correcto, la piedra cantaba" (Cal, 2010, p. 3). Contrario a los celtas, para la cultura griega la piedra significó lo inerte. Se asoció con lo inanimado y con el castigo que tenían que sufrir los seres humanos al trasgredir las reglas de los dioses. El mito cuenta que Prometeo tenía que vivir amarrado a una piedra eternamente mientras el buitre comía su hígado cada día como castigo por su trasgresión. No obstante, para la cultura hebrea la piedra también ha tenido este sentido de lo eterno y ha sido relacionada con Dios, "Rock, the most common biblical metaphor for reliability is often the living force of God manifested by water springing from the rock struck by the rod of Moses" (Tresidder, 2004, p. 416). En algunos de los salmos de David, la fuerza divina de Dios es comparada como la roca que salva y que protege. De la misma manera, para los cristianos, Jesús es la roca, la fuente de vida eterna. La edificación de la iglesia cristiana, metafóricamente hablando, se dio bajo esos mismos principios, como se puede apreciar en este pasaje bíblico: "Pedro, tú eres piedra y sobre esta piedra edificaré mi iglesia" (Mat.16:18). Estos son solo algunos ejemplos incorporados para demostrar cómo el símbolo de la piedra ha sido utilizado por diversos grupos étnicos o culturales a través de la historia de la humanidad.

En la cultura maya, la piedra está relacionada con la vida. La piedra no es un elemento inerte. Por el contrario, guarda la memoria del pueblo, como lo resalta la poeta maya quiché Rosa Chávez en su poemario Piedra AB’AJ (2009). En esta maravillosa colección de poemas encontramos una voz poética que hace un llamado a su pueblo para rescatar la memoria del pasado, lo cual les permitirá a sus integrantes recuperar la identidad perdida. Vania Vargas, en la contraportada de la edición de Piedra $A B^{\prime} A J$, expresa que en este poemario se encuentra una "voz que nace de un silencio antiguo que se quedó vibrando en ese lugar interior donde subsiste la conciencia. Y desde allí brota una palabra, sencilla y clara". Este silencio antiguo está relacionado con los ancestros maya-quiché de Rosa Chávez, que esculpieron con palabras en las rocas toda una tradición y todo el sentir de su pueblo. La voz poética es capaz de urdir en ese pasado y plasmarlo en estos poemas, en donde no solo enfatiza el pasado sino también el presente de su pueblo. Este poemario está cargado de tradición, en la cual se mezclan rituales ancestrales que nos dejan apreciar la magia de un pueblo que tenía una cosmología muy diferente a la impuesta a la llegada del hombre blanco. La intención de la voz poética consiste en devolver a su gente la capacidad de sentirse parte de su propio mundo y romper con las ataduras que les han sido impuestas desde la conquista. Este aspecto es sumamente importante, porque la voz poética deja sentir que con el transcurrir de los tiempos esa magia, esa realidad maya quiché se ha roto. Ha quedado recubierta con las nuevas ideas o filosofías que ha impuesto el hombre blanco. En la voz enunciativa del poema hay una necesidad de ahondar en el pasado, para que resurja la voz de la conciencia de los ancestros. En el "Prefacio" del Popol Vuh, Dennis Tedlock afirma que los mayas han tratado de mantener sus tradiciones vivas, sus raíces y sus ritos. No han abandonado totalmente su mundo para asimilar por completo las ideas impuestas por los europeos: 


\begin{abstract}
The quiché people a Mayan language, say prayers to Mayan Mountains and Mayan ancestors, and keep time according to the Mayan calendar. They are also interested citizens of the larger contemporary world, but they found themselves surrounded and attacked by those who have yet to realize they have something to teach to the rest of us. For them it is not that the time of Mayan civilization has passed, to be followed by the time of European civilization, but that the two have begun to run alongside one another. A complete return to conditions that existed before Europeans first arrived is unthinkable, and so is a complete abandonment of indigenous traditions in favor of European ones (Tedlock, 1985, pp. 13-14)
\end{abstract}

La forma en el que los mayas conciben su mundo es sumamente necesaria para perpetuar sus raíces, las cuales deben ser trasmitidas a las futuras generaciones, porque un pueblo que no tiene conciencia de quien es, muere. En los poemas de Rosa Chávez podemos apreciar claramente este deseo de recuperar el orgullo por lo propio. Como expresa Eduardo Galeano en Memorias del Fuego, "a lo largo de los siglos, América Latina no solo ha sufrido el despojo del oro y de la plata, del salitre y el caucho, del cobre y el petróleo: también ha sufrido la usurpación de la memoria. Desde temprano ha sido condenada a la amnesia por quienes le han impedido ser" (1982, p. XV). Recobrar esa memoria es sumamente importante y necesaria, de forma especial para los pueblos indígenas que se vieron despojados de sus prácticas culturales y religiosas a partir de la llegada de los conquistadores. La imposición de la nueva cultura trajo consigo un desbarajuste en los pueblos amerindios y por eso se hace tan necesario este rescate de la memoria. Por lo tanto, en el presente trabajo, se pretende realizar un análisis general del poemario, para después puntualizar algunos poemas que enfatizan esa búsqueda y en la recuperación de la identidad del pueblo maya a través de sus tradiciones y creencias.

Esta colección de poemas está dividida en cuatro secciones, complementarias entre sí. Se concuerda con Vargas cuando señala que: "estos poemas tienen mucho de ceremonia, de meditación individual del ser humano con su esencia y su naturaleza. Poesía que tiene mucho de ritual, en el que confluyen los elementos que conforman una manera ancestral de relacionarse con el mundo" (contraportada). Es claro que la herencia maya prevalece en la creación de estos poemas. Por esta razón, encontramos un gran énfasis en sus tradiciones, costumbres y ceremonias. De la misma manera, se resaltan sentimientos encontrados entre los que se encuentran la angustia, la tristeza, la impotencia, la rabia frente a la esperanza, el amor y el deseo. Estos elementos se pueden observar en el poema denominado "Agua":

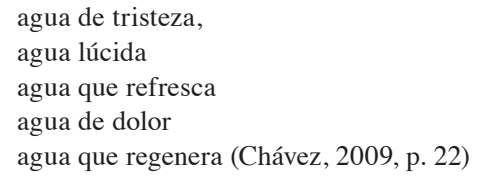

Los poemas no mantienen una secuencia específica, pero sí entretejen perfectamente conceptos culturales, familiares y sociales, lo cual da unidad a la temática, a la vez que enfatiza la tradición de su pueblo. El formato de los poemas es variado. Algunos poemas son breves, compuestos de uno, tres o cinco versos sin rima. El estilo se asemeja al haiku. También encontramos poemas más extensos que van desde ocho hasta treinta y seis versos. Otro aspecto interesante de esta colección es que casi todos los poemas están expresados en dos lenguas, en el español y el maya quiché. Lo cual resalta aun más el respeto por su cultura y sus ancestros. En general, son poemas que están plasmados de un lenguaje sencillo pero poderoso, lleno de imágenes diáfanas y precisas porque la voz poética quiere trasmitir y compartir un mensaje con su pueblo y con sus lectores. 
El poemario se abre con una dedicatoria muy significativa: "a quienes escarbamos con las uñas para encontrar nuestra piedra" (Chávez, 2009, p. 9). Desde el principio queda establecido que los poemas van dirigidos a un determinado grupo de personas, entre las cuales se encuentra incluida la misma poeta: "a quienes escarbamos". En otras palabras, a aquellas personas que están buscando con uñas y dientes eso que se ha quedado extraviado por el camino. La búsqueda por la identidad maya es esencial para la voz lírica. Se necesita escarbar en el pasado, en la memoria colectiva del pueblo para afianzar sus vidas. No se puede perder la identidad si se quiere seguir viviendo. Tienen que recuperar "nuestra identidad" o sea la historia del pueblo para continuar con la lucha. Aquí la piedra tiene una relación estrecha con el alma del pueblo. Chevalier dice que "La piedra, como elemento de construcción, está ligada a la sedentarización de los pueblos y a una especie de cristalización cíclica. Desempeña un papel importante en las relaciones entre el cielo y la tierra" (Chevalier, 2009, p. 828). La connotación que reviste el símbolo de la piedra, en este contexto, podría tener varios significados. Si lo observamos desde la colectividad, esa piedra puede entenderse como la piedra angular en donde se debe cimentar su cultura, que se ha visto desvalorizada con la intromisión del hombre blanco. La civilización maya, como el resto de las culturas aborígenes del Nuevo Mundo, construyeron sus pueblos alrededor de un templo o altar forjado, en una piedra ceremonial en donde se llevaban a cabo los ritos para sus dioses, como las estelas mayas que se encuentran en sus ciudades ancestrales tales como Tikal, Chichen Itza, Palenque y Copan.

Por otra parte, lo anterior se puede ver desde un ángulo más personal. La piedra viene a ser el redescubrimiento de su propio ser. Es una recuperación de su vida y sus costumbres, que se vieron opacadas con la imposición de otra cultura.

Como se menciona anteriormente para los mayas, la piedra también simbolizaba la memoria del pueblo, porque era donde se tallaban los diferentes acontecimientos políticos, sociales y cosmológicos que les concernían. Además, la piedra es un símbolo de permanencia. Magda Victoria Rodríguez explica que el jade, por ejemplo, era valiosísimo para los mesoamericanos, con valor superior al del oro:

\footnotetext{
"Mi amor por ti es tan eterno como el jade". Así reza una estela donde un príncipe maya declara su amor. El jade de los olmecas, mayas y aztecas era símbolo de eternidad, ya que tiene la misma apariencia a medida que pasen los años. La importancia de las piedras y los minerales en Mesoamérica radicaba no sólo en los usos que se les daba sino en que en muchos casos se les relacionaba con el Universo (Rodríguez, 2011, párrs. 2-3)
}

El primer poema que se analiza es el de apertura del poemario. Es sumamente significativo, porque indica el principio del fin de la cultura maya. Se titula "Las piedras fuimos marcadas con hierro candente", sinécdoque del sujeto maya. Con la llegada del hombre blanco, la cultura se vio alienada completamente. Echaron a los indígenas de sus tierras, los marcaron como se marca a los animales, y les robaron toda su libertad y la posibilidad de ser: "quemados nuestros ojos/ vimos con la mirada volteada/ agujeros negros" (Chávez, 2009, p. 10). Es importante apreciar aquí cómo la voz poética deja ver cómo a su cultura se le robó la capacidad de mirar con sus propios ojos. Los ojos son la ventana al mundo y ellos ya no tenían esa posibilidad de mirar con libertad lo que les rodeaba. No podían tomar sus propias decisiones y lo único que podían mirar era oscuridad. La muerte se convirtió en una constante en sus vidas. Sin embargo, este concepto en este poema no aparece como algo aterrador, sino más bien se le personifica como una amiga que los consolaba en sus infortunios: "la muerte chineaba nuestras desgracias" (Chávez, 2009, p. 10). Aquí aparece como la única salida al 
tormento. La imagen es sumamente maternal pues se pone a la muerte casi en el lugar de la madre que acurrucaba y que consentía los infortunios por los cuales estaban pasando. Todas estas desdichas van lacerando la conciencia y hasta los perros lamen sus heridas. La voz poética deja ver cómo se pierde la comunión con el mundo que habitan los descendientes mayas: "ya el sabor de la tierra no era el mismo/ los frutos caían antes de madurar” (Chávez, 2009, p. 10). Todo su mundo quedó trastocado. Se pierde la comunión con la naturaleza que era y sigue siendo esencial para los pueblos indígenas, ya que es la manera que tienen de relacionarse y entender el medio que los rodea. Esta situación de desposesión los obliga a buscar una manera de sobrevivir, que encuentran en la introspección. Aprenden a vivir dentro de una cueva interior: "A escondidas fuimos creciendo/ Gota a gota en lo profundo de las cuevas/ Así fue como nos envolvió el silencio/ Del gran comienzo" (Chávez, 2009, p. 10). Es el inicio de la nueva vida que les fue impuesta por los extranjeros que como ya se mencionó, fueron marcadas "con hierro candente" (Chávez, 2009, p. 10) y sellaron sus labios.

El final del poema deja ver dos aspectos importantes. Por una parte, al pueblo lo atrapó el silencio, porque ya su voz no tenía ningún valor en la nueva sociedad. Ya no tenían nada que expresar, nada que compartir, porque se les consideraba inferiores. Nótese como estas últimas estrofas denotan una gran amargura, una gran tristeza, porque su pueblo se ensimismó para poder subsistir a la opresión del invasor. Dentro de la cueva interior, lo que ven es un mundo de apariencia, ya no es el mundo en el cual estaban acostumbrados a vivir. Les han cambiado sus dioses, sus costumbres, sus tradiciones, pero ellos han podido "a encondidas" mantener vivas sus creencias y seguir luchando en un mundo que se ha vuelto adverso, pero que aún les pertenece, aunque la cultura invasora no los quiera reconocer como parte de ese mundo.

En el próximo poema se puede apreciar cómo una voz ancestral le hace un llamado a su pueblo a no olvidar los agravios que han sufrido a través de la historia y el precio tan alto que han tenido que pagar. Ahora viven en un mundo nuevo, donde hay edificios, carreteras, tienen todas las comodidades del mundo moderno. Las personas miran a los indígenas como si fueran ciudadanos de segunda categoría, como si nunca hubieran contribuido a la creación de las naciones a donde pertenecen. Por eso, la voz ancestral del poema le recuerda al pueblo maya actual que "Esta carretera también es tuya mija/ la pagó mi esclavitud" (Chávez, 2009, p. 68). La insta a que no olvide lo que han tenido que sufrir sus antepasados: "Me obligaron a picar piedra,/ la seña de las cadenas en mis tobillos, ahora nadie se acuerda" (Chávez, 2009, p. 68). En estos versos la piedra tiene una connotación totalmente diferente, puesto que aquí la piedra es símbolo de la esclavitud, del trabajo forzado que les obligaron a hacer los conquistadores en la construcción de caminos y edificaciones.

Pero ella, la voz poética, sí debe recordar. Es el mundo al que pertenece, es el mundo de sus ancestros. Un mundo por el cual pagaron con creces. Les arrebataron sus tierras y les hicieron trabajar en ellas como esclavos. Claro dice la voz ancestral: "ahora nadie se acuerda" (Chávez, 2009, p. 68). Pero eso no significa que no haya sucedido el proceso de desposesión.

La importancia de recordar en este poema es mantener vivo el origen. No es un llamado a la venganza o al odio. Se enfatiza la necesidad de salvaguardar el orgullo por la propia identidad nacional. Por lo tanto, la nación que ahora habitan también les pertenece.

El siguiente poema que se examina es "Dame permiso espíritu del camino". Este poema se observa como una oración ritualista en la cual se le pide permiso a los elementos de la Tierra para echarse a andar por el camino. Se deja ver cómo la voz lírica es consciente de que el 
mundo de sus ancestros ya no es el mismo, porque la mano del hombre blanco lo ha cambiado, pero la esencia todavía se encuentra en los elementos escondidos: "Regálame permiso/ para caminar/ por este sendero de cemento/ que abrieron en tu ombligo" (Chávez, 2009, p. 14). El interlocutor de este poema es la madre tierra. La voz poética reconoce que el invasor ha destruido la naturaleza, lo cual lo ejemplifica con la ruptura que le hicieron en el ombligo.

La voz lírica en este poema quiere comenzar de nuevo y terminar con "esta rabia que desorbita mis ojos" (Chávez, 2009, p. 14). Está deseosa de darle un nuevo sentido a la vida y que toda esa rabia "se me salga en palabras dulces" (Chávez, 2009, p. 14). Por eso pide permiso a todos los elementos de la Tierra, a las plantas, a las piedras para poder con palabras "finas, zarandeadas, reventadas" (Chávez, 2009, p. 14) expresar todo lo que se tiene que decir antes de que la naturaleza sea la que se rebele ante el silencio que ha caracterizado a su pueblo. Ella desea reencontrarse con su mundo. Quiere regresar a casa porque es el lugar a donde verdaderamente pertenece. Y sabe que tiene una misión que cumplir, ser la voz de su gente

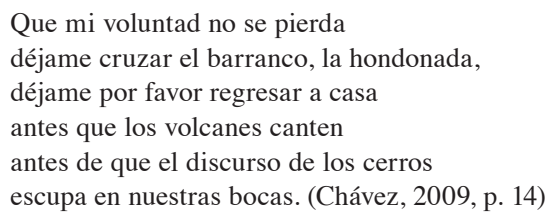

Siguiendo con este mismo pensamiento, se encuentra este poema que habla del por qué ella se encuentra tan ligada a la tierra y a su gente. Su abuelo le consagró a la naturaleza y le brindó la oportunidad de ser quien es hoy en día: una mujer fuerte que sabe luchar por lo que quiere y sobre todo sabe sobre guardar las tradiciones de su pueblo:

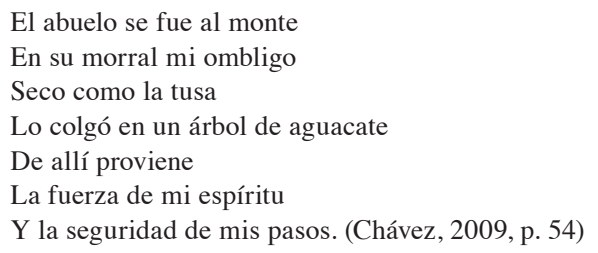

De nuevo en este poema, se aprecian los rituales de sus ancestros, que continúan vigentes hasta nuestros días. El abuelo perpetúa las tradiciones de su pueblo y de su familia para poder mantener viva la memoria y enseñarle a la nieta el camino que debe seguir y la importante misión que debe de cumplir para con su gente. La fuerza le viene de la conexión que ella tiene con la naturaleza por medio de su ombligo que su abuelo se lo ofrendó a la naturaleza como símbolo de un lazo entre su nieta y la madre tierra.

Un poema muy significativo es "Elena me llaman". Este poema está compuesto de seis estrofas, pero encierra toda una queja ancestral. La poeta dice que se le ha llamado Elena por la abuela y por la madre. Ella continúa con la tradición familiar de llevar no solo el nombre de las mujeres por la línea materna sino también de continuar y cargar con sus tradiciones y su historia. Se dice que el nombre con que una ha sido designada marca la clase de persona que una ha de ser. Aquí la voz poética se rebela en contra de esta tradición y reclama: "Acaso no merecía/ Un nuevo nombre/ Y crear mis propias desgracias" (Chávez, 2009, p. 18).

"Crear sus propias desgracias" se puede ver en este poema como el deseo de labrarse su propio destino. Ser merecedora de ser ella misma sin tener que arrastrar las culpas o los errores de los demás. Aquí la búsqueda de identidad es más personal y más fuerte porque 
aunque las tradiciones culturales son importantes, la poeta manifiesta un deseo de cambio pero de tipo personal.

El poema "Me siento triste y culpable", hace pensar más en una forma de queja por los problemas que le vienen del mundo. La voz poética siente que hay algo exterior que la agrede, que la hace sentirse cansada, enferma. No logra comprender con claridad qué es lo que le hace tanto daño. Ante su incapacidad para explicar lo que siente, o comprender las razones por las cuales se siente tan mal, explica que está enferma de susto. Aún más, dice "estoy ojeada/ tengo mal de ojo" (Chávez, 2009, p. 32). Esta explicación denota un aspecto cultural ancestral y que resalta una perspectiva maya quiché, cuando no se encuentra una explicación lógica a los padecimientos físicos se busca explicación en lo mágico. El componente mágico se puede apreciar más fácilmente en el mundo de las tradiciones, ya que en las culturas aborígenes se usó más para expresar la diferencia entre el bien y el mal, como lo expone Luis Beltrán:

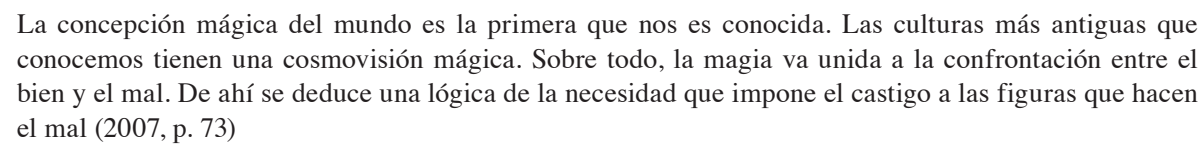

El mal de ojo es una creencia que muchas culturas ancentrales comparten. En este poema, por lo tanto, se puede ver cómo la superstición juega un papel muy importante. Un aspecto interesante es que ella dice que su mal de ojo no es "el de los patojitos" (Chávez, 2009, p. 32). En otras palabras, no es el mal de ojo que todos conocemos, porque no es el que le da a los niños. Recuérdese que en las culturas indígenas es importante proteger a los niños de los ojos malos de los adultos para que no los enfermen. Pero en este caso, este mal de ojo es "de la gente grande". Es una enfermedad que viene de afuera. La voz poética no lo dice explícitamente pero la enfermedad que tiene le viene del mundo que la rodea: "mi problema viene de afuera" (Chávez, 2009, p. 33). En otras palabras, todo lo que la enferma está causado por otros adultos que con sus acciones enferman la sociedad y por ende a las personas que habitan ese mundo. El mal de ojo lo recibe la cultura dominante en su sociedad que no los comprende y los aniquila social, física y emocionalmente. La descripción que da la voz lírica de cómo se siente es como una depresión causada por la impotencia de vivir en un mundo que ya no le pertenece.

Siguiendo esta temática encontramos con un breve poema que habla de una persona, que de acuerdo a la voz lírica, nació marcada por el mal. Es mala por naturaleza y por lo tanto todo lo que toque le dará mala suerte:

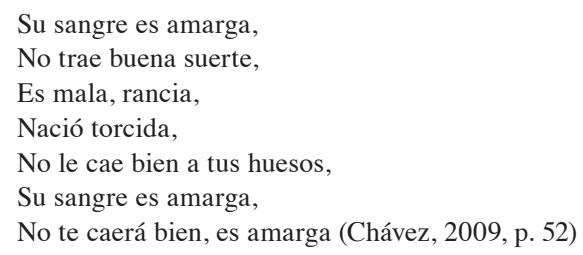

El verso "nació torcida" nos muestra un aspecto determinista de la cultura maya. Ella no tiene la posibilidad de cambiar su condición ya que nació marcada: "su sangre es amarga". Es su propia esencia y no existe manera de cambiar su destino. Por lo tanto, le avisa a la otra persona que se aleje de ella porque su compañía no le traerá nada bueno: "no te caerá bien, es amarga". Continuando con la tonalidad del poemario, se podría argumentar que la voz lírica se está refiriendo a las personas que le han hecho tanto daño a su pueblo a través de los tiempos. Tienen mala entraña y lo mejor que puede hacer su pueblo es mantenerse lejos de su influencia. 
El último poema que se analiza en este trabajo es el que concluye la colección. Se titula "La conciencia de la piedra". En este poema claramente se puede ver cómo la piedra es un símbolo vivo y parte esencial en la vida de los maya quiché.

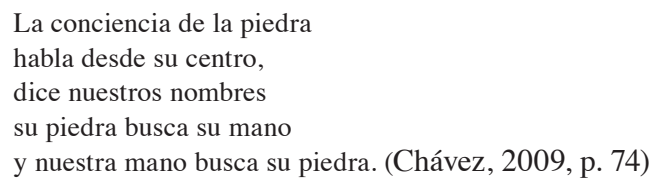

En estos versos se observa una gran comunión entre la piedra y los seres humanos. La piedra aparece aquí como la conciencia de las personas. Desde su centro, desde su corazón nombra a cada una de las personas y busca estrechar lazos de hermandad. La piedra guarda en ella la memoria de todas las generaciones, por ese motivo "en su centro guarda nuestra suerte/ nuestro duro destino/ nuestro blando destino" (Chávez, 2009, p. 74). La voz lírica, al final del poema, se vuelve más íntima y cambia la voz poética colectiva por una individual para reconocer su relación personal con su propia piedra, con su propio destino: "mi piedra y yo nos atravesamos" (Chávez, 2009, p. 74). Se puede apreciar aquí cómo el espíritu de la piedra y su propio ser se funden, a pesar que muchas veces la rechazó y la quiso muy lejos de sí. Sin embargo, ésta regresa a ella "fragmentada/ lengüeteada por el sol" (Chávez, 2009, p. 74 ). Y ella se da cuenta que debe aceptar su destino abrazándola, recibiéndola dentro de su ser para que ninguna de las dos se pierda en este mundo. Piedra y ser humano son una misma cosa como lo indica el poema que dedica a su hijo

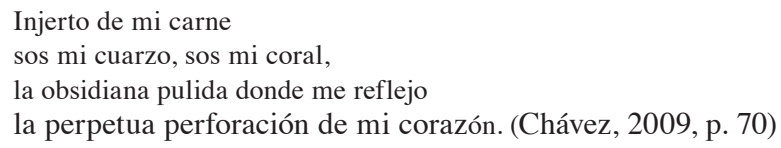

Como se ha podido apreciar en este breve acercamiento a la poesía de Rosa Chávez, el símbolo de la piedra es sumamente importante para la cultura maya quiché. A diferencia de los griegos la piedra no es un elemento muerto, ni causa la muerte y mucho menos el castigo. La piedra es sinónimo de vida. Es la esperanza del pueblo porque ella guarda la memoria de la gente. La voz poética hace énfasis en la colectividad porque la piedra representa a cada uno de los miembros de su pueblo pasado, presente y futuro. Ella guarda la historia y es precisamente la recuperación de esa historia la que quiere reafirmar a través de las páginas de este poemario. Por esta razón está lleno de ritos ancestrales, de tradiciones, de recuerdos de lo que un día fueron y de la esperanza de lo que un día pudieran volver a ser. Ella es la esperanza de su gente porque su poesía está cincelada en la piedra: "Escrita en piedra está mi voz,/Mi cordón,/Los nombres de los nombres" (Chávez, 2009, p. 16).

\section{Bibliografía}

Beltrán, L. (2007). Magia y Simbolismo. Por S. Callau (Ed.). Culturas Mágicas: Magia y Simbolismo en la Literatura y la Cultura Hispánicas. (71-82). Zaragoza: Prames.

Cal, C. (2010). La Piedra de Scone. http//cal-investiga.tripod.com/id2.html [Consulta 10 de octubre de 2014].

Chávez, R. (2009). Piedra AB’AJ. Guatemala: Editorial Cultura. 
Chevalier, J. y Gheerbrant, A. (1986). Diccionario de los símbolos. Barcelona: Herder Editorial. Galeano, E. (1982). Memoria del fuego (I) Los nacimientos. Mexico D.F: Siglo Veintiuno. La Biblia. (2003). Dios Habla Hoy. Sociedades Biblicas Unidas.

Popol Vuh. (1985). (D. Tedlock, tr.). New York: Simon and Schuster Inc.

Rodriguez, M. V.(2011). El jade para los pueblos mesoamericanos. http://www.diariodelviajero. com/america/el-jade-para-los-pueblos-mesoamericanos [Consulta 15 de octubre de 2014].

Tresidder, J. (2004). The Complete Diccionary of Symbols. London: Duncan Baird Publishers. 
